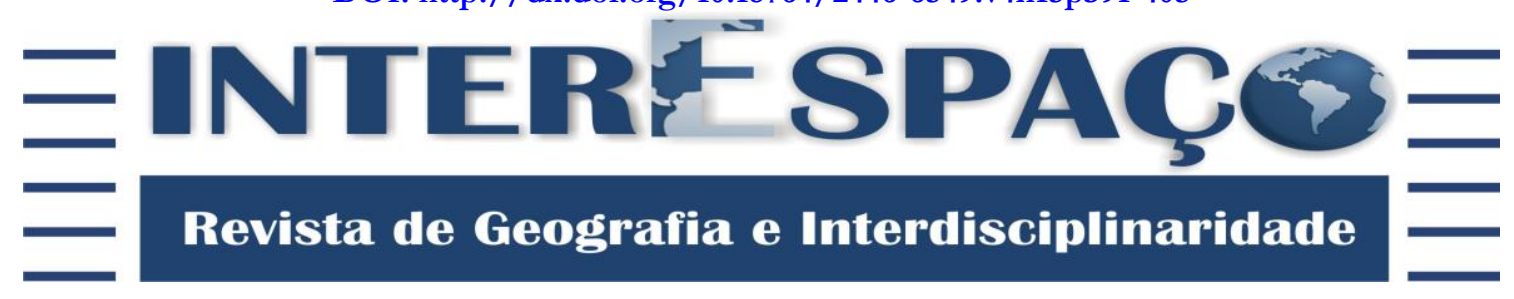

\title{
GEOGRAFIA E ENSINO: um olhar humanista
}

\author{
GEOGRAPHY AND TEACHING: a humanist look
}

\section{GEOGRAFÍA Y ENSEÑANZA: una mirada humanista}

\author{
Felipe Kevin Ramos da Silva \\ Mestre em Geografia pela Universidade Federal do Pará - UFPA. Professor da Universidade Norte \\ do Paraná - UNOPAR/Polo Belém/PA. \\ felipekevin.geografia@gmail.com
}

Recebido para avaliação em 20/07/2018; Aceito para publicação em 21/11/2018.

\begin{abstract}
RESUMO
Pensar o ensino de geografia a partir do bumanismo é o objetivo deste breve ensaio. Tendo em vista que o ser humano é essencialmente um ser geográfico, busca-se, teoricamente, refletir sobre a relação ensino-geografia enquanto dimensão indissociável no qual a subjetividade humana torna-se o ícone referencial. Nesse sentido, a Geografia humanista revela-se como guia deste ensaio sob a regência da perspectiva fenomenológica existencialista. No entanto, não necessariamente iremos fazer um balanço sobre as principais teorias do ensino de geografia, mas, sobretudo, trazer ao leitor, autores que possam, em tese, nos possibilitar a (re)pensar o ensino de geografia mais em sua dimensão ontológica e epistemológica, que propriamente lógica e apriorística.
\end{abstract}

Palavras-chave: Fenomenologia; Ontologia; Geografia Humanista.

\section{ABSTRACT}

Thinking about the teaching of geography from humanism is the goal of this brief essay. Considering that the human being is essentially a geographic being, it is theoretically sought to reflect on the teaching-geography relationship as an inseparable dimension in which human subjectivity becomes the referential icon. In this sense, humanist geography reveals itself as a guide to this essay under the regency of the existentialist phenomenological perspective. However, we will not necessarily take stock of the main theories of geography teaching, but above all, bring to the reader, authors who can, in theory, enable us to (re)think geography teaching more in its ontological dimension and epistemological, that properly logical and aprioristic.

Keywords: Phenomenology; Ontology; Humanist Geography.

\section{RESUMEN}

Pensar la enseñanza de la geografía a partir del humanismo es el objetivo de este breve ensayo. Teniendo en cuenta que el ser humano es esencialmente un ser geográfico, se busca, teóricamente, reflexionar sobre la relación enseñanza-geografía como dimensión indisociable en el que la subjetividad humana se convierte en el icono referencial. En ese sentido, la Geografía humanista se revela como guía de este ensayo bajo la regencia de la perspectiva fenomenológica existencialista. Sin embargo, no necesariamente vamos a hacer un balance sobre las principales teorías de la enseñanza de geografía, pero, sobre todo, traer al lector, autores que puedan, en tesis, permitirnos (re) pensar la enseñanza de geografía más en su dimensión ontológica y, epistemológica, que propiamente lógica y apriorística.

Palabras clave: Fenomenología; Ontología; Geografía Humanista. 


\title{
INTRODUÇÃO: entrando em sala de aula...
}

\begin{abstract}
"Humanismo, porque lembramos ao homem que não há outro senão ele mesmo, e que é no desemparo que ele decidirá por si mesmo; e porque mostramos que não é voltando-se para si mesmo, mas sempre buscando fora de si um fim que consiste nessa liberação, nesta realização particular, que o homem se realizará precisamente como humano".
\end{abstract}

Jean-Paul Sartre

O filósofo francês Jean-Paul Sartre, fortemente influenciado pela fenomenologia de Martin Heidegger, nos apresenta o humanismo como princípio elementar para pensar a realidade humana a partir de sua construção factual, isto é, o ser enquanto ser histórico, finito e social, ao modo que a existência antecede a essência numa "relação ontológica", como diria Lévinas (1997). Ou seja, o humanismo como bússola norteadora a caminho da alteridade, fundamento essencial para compreender a si mesmo e os outros entes no mundo circundante ${ }^{1}$. O presente artigo Geografia e ensino: um olhar humanista, portanto, é uma tentativa de anunciar a urgência de considerar no planejamento do/no/para o ensino da ciência geográfica uma postura de sensibilidade com os lugares (míticos), afinal, é no contato com outros lugares que nossa essência, de forma indeterminante, se transforma como forma de ser, no mundo, como demostra Dias (2015; 2016).

Nesse sentido, e tendo como horizonte epistemológico a Geografia Humanista sob a regência da fenomenologia ${ }^{2}$, entendemos que o ser humano é essencialmente ser geográfico, ao modo que este se faz existir a partir de uma dada conjuntura de experimentações/percepções espaciais no mundo, como aponta Marandola Jr. (2015), fundamentando àquilo que Dardel (2015) chamou de "experiência geográfica". A experiência $^{3}$ geográfica, nessa conjuntura, ganha uma conotação ontológica em geografia

\footnotetext{
1 “[...] falar de mundo circundante não é dizer que o mundo é primitivamente espacial (pois não foi extensio reconhecido a partir de Descarte como a característica essencial da natureza e do mundo?). Para além de a preposição Um- não significa exclusivamente à volta, mas também para, o mundo não pode receber a sua espacialidade a não ser do ser mundo. O espaço não é compreensível a não ser a partir da mundaniedade porque o espaço é no mundo e não o mundo no espaço" (FRANK, 1997, p. 51).

2 Segundo Edward Relph: "O método fenomenológico é um procedimento para descrever o mundo cotidiano da experiência imediata do homem, incluindo suas ações, memórias, fantasias e percepções; não é um método de análise ou de explicar algum mundo objetivo e racional, através do desenvolvimento de hipóteses anteriores e teorias. Na descrição do mundo da experiência, ou para usar a expressão de Husserl, no retorno às próprias coisas como objetos de experiência do homem, afirma-se que esses objetos não podem existir independentemente da consciência do homem. O a priori assunção de Descartes, que existe um mundo objetivo, que possui uma racionalidade que pode ser compreendido e que é independente do homem, é assim considerado inválido; todo conhecimento procede do mundo da experiência e não pode ser independente desse mundo" (RELPH, 1970, p. 193).

${ }^{3}$ A experiência será trabalhada aqui em sua essência, em seu sentido primeiro, ontológico, com base em Dardel (2015). É algo que nos remete a pensar a experiência enquanto experimentação do ser em sua totalidade existencial no espaço, ressaltando a importância de dimensões sensíveis como a cinestesia, visão e tato, conforme Tuan (2013), ou seja, a importância das cores, dos cheiros e dos sabores, como nos ensinam Gratão e Marandola Jr. (2012).
} 
na medida em que, segundo Heidegger (1988), o ser do homem já encontra sempre uma espacialidade própria no mundo para poder "ser-no-mundo" e, dentro dessa transcendência, enquanto ente, projeta sua existência na medida em que "organiza seu espaço e lugar" (TUAN, 2013).

O humanismo e o princípio da alteridade, com base em Sartre (2014) e Lévinas (1997), respectivamente, e as concepções de habitar, percepção e espaço geográfico de Heidegger (1988), Merleau-Ponty (1994) e Dardel (2015), serão nossas dimensões-guias para pensar $^{4}$ a relação ensino-geografia. O humanismo, segundo Sartre (2014, p. 34), trata de anunciar um empreendimento existencial e, portanto, um mundo tal qual nossa experimentação geográfica o solicita, sob o qual "chamaremos de intersubjetividade", algo possível somente por meio do "engajamento corporal”, conforme Merleau-Ponty (1994) e, portanto, o homem tomando consciência daquilo que ele é e o que os outros são. Nestas condições, a experiência geográfica é a realidade humana na medida em que o ser do homem se faz existente na anunciação de sua própria condição humana neste mundo, desvelando, em meio a este diálogo, sua "geograficidade" (DARDEL, 2015).

Em meio à relação entre ensino e geografia, o que se desvela na complexidade deste “entre"? - É este "entre" que, de um modo geral, o artigo irá se articular com o objetivo de contribuir para novas estratégias no ensino de geografia. É neste "entre" que tentarei esboçar, as potencialidades das experiências humanas para/no ensino de geografia, anunciando, por este caminho, seu caráter ontológico para (re)pensar a geografia a partir daquilo que chamaremos de experimentação geográfica. Temos, nesse momento, uma linha de pensamento que se intersecta como abertura ao ensino de geografia e não simplesmente "ensinar geografia" de caráter determinante, simplesmente "dado" e fragmentado no campo das certezas, típico do pensamento positivista. Há necessidade, portanto, do distanciamento do "campo das certezas", isso porque "[...] quando conservamos e descobrimos novos arquipélagos de certezas, devemos saber que navegamos em um oceano de incertezas" (MORIN, 2012, p. 59).

\section{O SENTIDO DO SENTIDO DA GEOGRAFIA}

\begin{abstract}
“[...] a geografia não é, no fim das contas, uma certa maneira de sermos invadidos pela terra, pelo mar, pela distância, de sermos dominados pela montanha, conduzidos em uma direção, atualizados pela paisagem como presença da Terra?”
\end{abstract}

Eric Dardel

\footnotetext{
${ }^{4}$ Neste sentido, queremos dizer que “[...] pensar não é mais contemplar, mas engajar-se, estar englobado no que se pensa, estar embarcado - acontecimento dramático do ser-no-mundo” (LÉVINAS, 1997, 25).
} 
Sob a orientação fenomenológica, assumo minha postura enquanto geógrafo que pensa a geografia enquanto ciência da "descrição direta de nossa experiência tal como ela é” (MERLEAU-PONTY, 1994, p. 1-2), com o objetivo de trazer à reflexão a importância dos laços maternos que há entre cada homem e mulher com seu lugar como "habitaçãoconstrução" ${ }^{5}$ e, por conseguinte, base e meio de todas as realizações humanas. Trata-se de ressalvar, quantas vezes for possível, a existência de uma relação cósmica e telúrica entre o ser que somos, nossas ações e o mundo circundante. Em outras palavras, com base em Dardel (2015, p. 40 [inspirado em Merleau-Ponty]), “a geografia se dirige, além do saber e da inteligência, ao próprio homem como pessoa e sujeito. Um elemento onde o homem não é o mestre interventor, geralmente inconsciente, na sua experiência geográfica”. De um modo geral, esta é a sedimentação epistemológica para pensar o sentido do sentido da geografia, isto é, sua essência por meio da experiência geográfica do/no meio ambiente, como também nos orientam Tuan (2013) e Oliveira (2017).

Como pensar a experiência humana como ícone referencial para o ensino de geografia? O que devemos levar em consideração antes de formular nossos planejamentos de ensino, nossas aulas? Que significa trazer ao debate geográfico o valor do lugar enquanto potencialidade do ser? E como o humanismo, anunciado pela fenomenologia, pode contribuir para tais questões? Antes de mergulharmos nessas reflexões, é necessário dizer, mesmo que minimante, o que entendemos por geografia. Lívia de Oliveira inspirada, sobretudo, em Yi-Fu Tuan, escreve um artigo intitulado Que é Geografia (1999), algo que nos estimula a pensar esta ciência como instrumento transformador da realidade e, além disso, nos traz a consciência acerca da importância da geografia em seu aspecto humanista, ao dizer, por exemplo, que "não se pode esquecer que o desenvolvimento da noção de espaço está submetido ao fator idade, variando desde crianças, adolescentes, adultos, até os mais velhos" (OLIVEIRA, 1999, p. 91).

A relação ensino-geografia deve ser entendida da mesma forma que o “distanciamento-aproximação" desenvolvido por Heidegger (1988). Em outras palavras, tornar-se-á mais coerente falarmos de ensino-geografia, como algo indissociável, verbalizado na dimensão da realidade humana que exige de nós um eterno refazer-se no mundo. Segundo Tuan (2013), aprendemos sobre o mundo que nos cerca desde a infância,

\footnotetext{
5 "Esta máxima é importante à compreensão da casa como dimensão ontológica do ser geográfico [...]. Porém, não é somente no sentindo material em si que as coisas se constituem, mas na conjuntura cultural de onde se origina a materialidade construída em termos de significação. A casa, um lugar das primeiras relações do ser com o mundo, como nos lembra Bachelard (1978), é uma construção material, concreta no espaço, no entanto, é também o primeiro espaço de socialização com o mundo e entendimento no qual se pertence a uma cultura: a casa como espaço sagrado para abertura/apresentação ao mundo [...], emergindo como negação de uma metafísica 'apressada', portanto, uma habitação-construção”' (SILVA, 2017, p. 116).
} 
nos primeiros passos na casa e com um simples levantar dos braços tomamos consciência da dimensão espacial sob o qual estamos inseridos. Nesse sentido, ressalvamos o ser geográfico que somos ao admiti que, desde muito cedo, aprendemos uma "geografia autêntica", como diria Dardel (2015), na simplicidade ou intimidade com nosso lugar - à Bachelard (1978). Esta intimidade geográfica, trabalhada pela topoanálise de Bachelard (1978) por meio da metáfora da "casa", nos alerta para a importância dos espaços no qual esboçamos nossos lugares seguros e os nem tanto assim.

Segundo Silva (2017), esboçar o lugar pelos espaços que andamos é anunciar nossa essência por meio da existência, uma certa "espacialidade", conforme Heidegger (1988), que desvela o ser para além de si mesmo como ser desejante e que, evidentemente, clama para que seu lugar se apresente como parte de sua intimidade existencial. A busca por este lugar, próprio, único, requer o contato com outros espaços e um certo engajamento de experimentação corporal entre os lugares. São nesses "entrelugares", como diria Bhabha (1998), que ensinamos e somos ensinados, dialogicamente, ao modo que neste "entre nós", emprestando um termo de Lévinas (1997), esbarramos naquilo que somos geograficamente: ser em transformação. Por isso, o ensino é um processo de modificação, atualização da consciência em transcendência de si para o mundo na constituição inquebrável homem-espaço ${ }^{6}$, apresentando a complexidade à consciência e esta, por sua vez, ao ensino (MORIN, 2012).

Nestas condições, torna-se fundamental perceber que o sentido da geografia está essencialmente ligado à complexidade que o mundo é e a uma dada conjuntura histórica que precede sua sistematização categórica, ressalvando, nesse aspecto, a mundaneidade ${ }^{7}$ presente em nossas interpretações - a relação umbilical do ser humano com a Terra, admitindo, por exemplo, a mitologia, a arte, a linguagem e, inclusive, a imaginação como formas das sociedades organizarem seus espaços, as "teias de significados" como diria Geertz (2008). Em outras palavras, as sociedades legitimam suas respectivas culturas a partir das experiências geográficas, sejam elas econômicas, míticas ou políticas - sendo algo que reflete no processo normativo do ensino. Portanto, ao contrário do que pregam os

\footnotetext{
6 "Quando se fala do homem e do espaço, entende-se que o homem está de um lado e o espaço de outro. O espaço, porém, não é algo que se opõe ao homem. O espaço nem é um objeto exterior e nem uma vivência interior. Não existem homens e, além deles, espaço. Ao se dizer "um homem" e ao se pensar nessa palavra aquele que é no modo humano, ou seja, que habita, já se pensa imediatamente no nome "homem" a demora, na quadratura, junto às coisas. Mesmo quando nos relacionamos com coisas que não se encontram numa proximidade estimável, demoramo-nos junto às coisas elas mesmas. O que fazemos não é simplesmente representar, como se costuma ensinar, dentro de nós coisas distantes de nós, deixando passar em nosso interior e na nossa cabeça representações como sucedâneos das coisas distantes” (HEIDEGGER, 1954, p. 7). ${ }^{7}$ Referente à conceituação que Heidegger emprega a mundaneidade, "no qual é o modo da presença das coisas" (FRANCK, 1997, p. 121).
} 
positivistas, a realidade humana não pode ser entendida a partir da "separação" do ser do homem com a Terra, pois esta é base e meio de sua realização geográfica no mundo circundante enquanto ser-no-mundo que aprende cotidianamente, entre choros e risos, entre erros e acertos, entre os lugares.

De um modo geral, o sentido do sentido da geografia numa perspectiva humanista, empreendimento que alguns geógrafos se dispuseram e se dispõem a realizar, tais como Dardel (2015); Lowenthal (1961); Relph (1970); Tuan (1976; 2011; 2012; 2013); Entriki (1980); Oliveira (1999; 2014; 2017); Cosgrove (2012); Buttimer (1969); Wright (2016); Marandola Jr. (2010; 2015); Silva (2009); Holzer (1998); e Silva (2015; 2017), por exemplo, diz respeito tanto aos nossos procedimentos de análise da realidade humana quanto à postura intelectual e, sobretudo, nossa responsabilidade ontológica com o outro, ressalvando, o princípio da alteridade, à maneira de Lévinas (1997). Nesse sentido, é necessário pontuar nosso "olhar" geográfico de mundo, que permeia o humanismo e é regenciado pela fenomenologia existencialista em caminho a uma ontologia geográfica do ser, ou seja, uma geografia que nos estimule a pensar o espaço geográfico enquanto linguagem da experiência perceptível humana, tendo como ícone referencial o "cotidiano, enquanto situação de e em trânsito" (PANTOJA, 2015, p. 225) - algo que ecoa (ou deveria ecoar) do/no ensino de geografia:

\footnotetext{
Enriquecida essa forma de pensar sobre a ideia de lugar, o professor poderá trabalhar o cotidiano do aluno com toda a carga de afetividade e do seu imaginário, que nasce com a vivência dos lugares. A nova abordagem poderá ajudar o aluno a pensar a construção do espaço geográfico não somente como resultado de forças econômicas e materiais, mas também pela força desse imaginário. Temas relacionados com a produção e o consumo dos espaços no campo ou na cidade e dos movimentos migratórios poderão abrir perspectivas de estudos entre o espaço e o conceito de cidadania, dentro de uma nova versão geográfica (BRASIL, 1998, p. 59 [Grifo nosso]).
}

Esta crítica que se faz ao "nascimento" da geografia enquanto ciência reverbera inúmeras dimensões e posicionamentos teóricos e práticos, na qual iremos ressaltar: a dimensão fenomenológica que, em nosso caso, não se arquiteta de maneira vazia e de conteúdo incoerente, mas, justamente por seu projeto inicial que, conforme Husserl (2006, p. 2), está em anunciar que "o conhecimento natural começa pela experiência e permanece na experiência". Quando incorporamos esta compreensão à geografia, estamos trazendo a importância de pensar a essência da ciência geográfica e, ao mesmo tempo, "uma tentativa de formular um método alternativo de investigação”, conforme Relph (1970, p. 193). A "História do Pensamento Geográfico", por exemplo, aparentemente só ganha um "sentido 
histórico" a partir do século XIX com Ratzel - esta concepção deságua do ensino básico ao Ensino superior, em pós-graduações, etc -, intimamente, excluindo a experiência humana, sob o qual Dardel (2015) considera fundamento essencial à ciência geográfica, as “geosofias", como diria Wright (2016). No entanto, isso é outra história...

Precisamos ir para além da concepção academicista e tradicional ${ }^{8}$, algo que o próprio Parâmetro Curricular Nacional de Geografia (PCN) já nos estimula a pensar, anunciando a fenomenologia, por exemplo, como meio de alcançar este objetivo e, portanto, um método alternativo de ensino a partir da valorização da subjetividade dos estudantes em sala de aula, quando se trabalha, sobretudo, os conteúdos introdutórios que envolvem as categorias espaço, lugar e paisagem (BRASIL, 1998). Nesse sentido, estamos caminhando em direção à "[...] uma Geografia que busca a dimensão da experiência enraizada numa ontologia que inclua o cuidado e a autenticidade do ser-no-mundo como traços fundamentais" (MARANDOLA JR., 2010, p. 8-9). Conforme este pensamento, a relevância de trabalhar o sentido do sentido da geografia no ensino encontra-se em estabelecer que a ciência geográfica, muito mais que meramente uma ciência dos lugares é, essencialmente, um empreendimento ontológico e cultural de homens, mulheres e crianças em suas relações íntimas com o lugar.

\section{O HUMANISMO COMO MOTOR DO/NO ENSINO DE GEOGRAFIA}

"É preciso saber começar, e o começo só pode ser desviante e marginal". Edgar Morin

O humanismo, sob a perspectiva fenomenológica, é o nosso motor para pensarmos o ensino de geografia, uma proposta que está vinculada com algumas problemáticas contemporâneas de herança histórica. As guerras, os conflitos geopolíticos, por exemplo, são algumas dessas questões que podem e, muitas vezes, são trabalhadas em sala de aula. No entanto, talvez, o grande diferencial de trabalhar estas questões em sala com enfoque humanista seja o de acentuar a importância de nossas ações no mundo e que apesar das nebulosidades políticas atuais, ainda há esperança. Esperança esta que permite o direito de

\footnotetext{
8 "Essa Geografia era marcada pelo positivismo que sustentava metodologicamente quase todas as chamadas ciências humanas que se consolidaram nessa época nas faculdades brasileiras. Com fortes tendências de estudos regionais, os estudos geográficos pautavam-se pela busca de explicações objetivas e quantitativas da realidade, fundamentos da escola francesa de então. Foi essa escola que imprimiu ao pensamento geográfico o mito da ciência asséptica, não-politizada, com o argumento da neutralidade do discurso científico. Tinha como meta abordar as relações do homem com a natureza de forma objetiva, elaborar monografias regionais para uma possível busca de leis gerais que explicassem suas diferenças. É importante lembrar que para La Blache a Geografia não era ciência dos homens, mas dos lugares" (BRASIL, 1998, p. 19).
} 
sonhar e, ao mesmo tempo, cabendo somente à humanidade tal decisão de assim ser ou não, como nos propõem Kropotkin (1885, p. 2), ao dizer que "a Geografia [...] deve nos ensinar, desde nossa mais tenra infância, que todos somos irmãos, independentemente da nossa nacionalidade".

Ainda sob a regência de Kropotkin (1885):

[...] Nestes tempos de guerras, de ufanismos nacionais, de ódios e rivalidades entre nações, que são habilmente alimentados por pessoas que perseguem seus próprios e egoísticos interesses, pessoais ou de classe, a geografia deve ser - na medida em que a escola deve fazer alguma coisa para contrabalançar as influências hostis - um meio para anular esses ódios ou estereótipos e construir outros sentimentos mais dignos e humanos. Deve mostrar que cada nacionalidade contribui com sua própria e indispensável pedra para o desenvolvimento geral da humanidade, e que somente pequenas frações de cada nação estão interessadas em manter os ódios e rivalidades nacionais (KROPOTKIN, 1885, p. 2).

P. Kropotkin relata suas experiências geográficas com enfoque no ensino durante o século XIX, e me parece que de lá para cá, muita coisa ainda insiste em permanecer, só que de forma mais sutil. A partir deste pensamento, é possível entender o fundamental projeto de ensino com base na percepção geográfica de mundo, da "responsabilidade"" com o outro; uma tentativa de anular o ódio, a rivalidade entre pessoas e nações, ou seja, a ciência geográfica, como nos ensina Oliveira (1999), deve ser pensada como um meio de transformação social, utilizando as experiências e percepções humanas como ícones para repensar a própria existência. Uma ontologia começa a se desvelar e que só pode vir a ser alcançada por meio da fenomenologia (HEIDEGGER, 1988). Significa dizer, portanto, que fenomenologia-ontologia-experiência-subjetividade-humanismo são dimensões interpenetradas com o objetivo de estimular, neste caso, um ensino de geografia que valorize a importância do "lugar" enquanto potencialidade do ser.

Vejamos, nesse momento, o que o PCN nos diz:

\begin{abstract}
Ao construírem os seus lugares, os homens constroem, também, representações sobre eles. Seu nível de permanência na vivência com as coisas, nas relações com as pessoas, vai definindo sua aderência a esses lugares. Por isso as migrações significam rupturas que muitas vezes deixam traumas. Esse fato pode ser muitas vezes agravado pela dificuldade de inserção nos novos lugares. Quando se migra, leva-se o imaginário do lugar de origem (BRASIL, 1998, p. 59).
\end{abstract}

E ainda:

\footnotetext{
9 “[...] O homem que se engaja e que se dá conta de ele não é apenas aquele que escolheu ser, mas também um legislador que escolhe simultaneamente a si mesmo e a humanidade inteira, não consegue escapar ao sentimento de sua total e profunda responsabilidade [...]" (SARTRE, 2014, p. 21).
} 
Com o seu trabalho, os homens constroem estradas, edifícios, campos cultivados, redes de esgotos, áreas de lazer, escolas, hospitais, teatros, mas nem sempre se apropriam deles. Embelezam os espaços públicos com as obras que constroem e povoam seu imaginário. Porém, são em grande parte excluídos deles (BRASIL, 1998, p. 59).

Estas passagens do PCN nos fazem lembrar Heidegger (1954), quando o filósofo afirma que o homem essencialmente habita um dado espaço construindo-o, no entanto, nem toda construção é necessariamente um habitar. Habitar requer, como nos ensina Nunes (2009), um “demorar-se", portanto, o homem só habita na "ocupação", diria Heidegger (1988), no espaço, em sua experiência sensível e latente. Mediante este pensamento, estamos chamando atenção para dizer que o espaço é construído essencialmente por experiências intersubjetivas que recorrem à consciência como meio de apropriação do espaço objetivo.

Segundo Silva (2017), “o espaço é um conjunto de choques entre existências e vários 'querer"', afinal, o ser é multiplicidade, conforme Morin (2015). Se o espaço geográfico é um empreendimento puramente humano, afirma Tuan (2013), podemos dizer que falar de espaço é falar dos conjuntos complexos recheados de intencionalidades (pensamentos/planejamento), de emoções. Esse "querer", que seria um "comandar", "na medida em que esse ato consciente supõe um ato inconsciente" (NIETZSCHE, 2010, p. 399) pode ser traduzido por aquilo que Eric Dardel em sua geografia fenomenológica anuncia como "geografia em ato":

\begin{abstract}
Mas antes do geógrafo e de sua preocupação com uma ciência exata, a história mostra uma geografia em ato, uma vontade intrépida de correr o mundo, de franquear os mares, de explorar os continentes. Conhecer o desconhecido, atingir o inacessível, a inquietude geográfica precede e sustenta ciência objetiva (DARDEL, 2015, p. 1).
\end{abstract}

O "querer" de Nietzsche (2010) é à vontade em potência do homem de se "lançar no mundo", como diria Dardel (2015), a novas aventuras, encontros com os signos ofertados pela Terra que sempre surpreendem aqueles que se dispõe de corpo e alma no mundo: os viajantes, aventureiros como o pequeno príncipe de Saint-Exupéry (2015). Ora, afinal, ser geógrafo não seria o ser aberto às incertezas no mundo? Parafraseando Ab’Saber (2007), ser geógrafo é muito mais uma questão de experiência do que propriamente um empreendimento academicista ${ }^{10}$. Estamos falando de uma geografia vívida que nasce no

10 “[...] Eles seguem as pegadas de outros, imitando padrões estereotipados e, se sua empreitada e habilidade imitativa forem consideráveis, podem ter sucesso em ensinar e até em pesquisar, servindo bem para manter a geografia como está e conduzi-la ao longo de trilhas batidas, se não para balizar as novas" (WRIGHT, 2014, p. 8). 
"campo do querer" como fala Nietzsche (2010), representada na "geografia em ato" de Dardel (2015). Nesse sentindo, antes de qualquer coisa, a geografia como "querer", "ato" ou "criação" é uma libertação da moral cientificista e, naturalmente, vinculada a uma proposta epistemológica para pensar o ensino de geografia como força que nasce genuinamente dos lugares (SILVA, 2017).

Nas palavras de Eric Dardel, podemos entender que "a geografia científica é também, num certo sentido, oposta à realidade geográfica que exige o esforço da vontade, o gosto pelo risco, uma certa abertura para a alegria ou para o prazer da novidade a ser desvelada” (DARDEL, 2015, p. 83): as incertezas. A geografia em ato, que é a nutrição epistemológica deste artigo, exige de nós, geógrafos, o entendimento que "não há ato perfeito que não seja ato instintivo [...] e é geralmente o contrário da moral' (NIETZSCHE, 2010, p. 359-360 [grifo nosso]). Essa crítica à ciência moderna se faz necessária na medida em que o mundo exige uma nova postura dos professores de geografia, na medida em que ser professor, como nos lembra Morin (2012, p. 101 [inspirado em Platão]), é trabalhar com amor pelo conhecimento e "é isso que, antes de tudo mais, pode despertar o desejo, o prazer e o amor no aluno e no estudante" para os estudos geográficos, em nosso caso, isso porque "onde não há amor, só há problemas de carreira e de dinheiro para o professor e de tédio, para os alunos" (Idem, p. 102).

\section{CONCLUSÃO}

"O corpo de ensino tem de chegar aos postos avançados do mais extremo perigo, que é construído pela permanente incerteza do mundo".

Martin Heidegger

Por uma questão de inovação e avanços do/no ensino de geografia devemos considerar a criatividade, a imaginação, as experiências como ícones referenciais. $O$ trabalho/pesquisa de campo, neste sentido, torna-se um recurso que perpassa pelo campo da ludicidade, mas também pela dimensão da experiência enquanto princípio geográfico, portanto, de conhecimento/percepção de mundo. Daí a pesquisa de campo como recurso no ensino de geografia é uma estratégia de trazer ao debate em sala as concepções précientíficas dos alunos, podendo tais concepções, que são experienciadas vividamente, enquanto possibilidade para refletir sobre as categorias geográficas, tais como espaço e território para além das relações unicamente de poder, dificultando a "educação geográfica”, como diria Kropotkin (1885). 
Nesse sentido, Juliana Dias com base no filósofo Gaston Bachelard, nos traz à reflexão algumas formas de superar tal "abstração" conceitual ao escrever, por exemplo, sobre a importância da imaginação e da percepção dos estudantes no ensino de geografia, nos convidando ao mergulho poético ofertado pela infância dentro da perspectiva fenomenológica, ao dizer que "a criança como filha do cosmos torna-se dona de seus devaneios e conhece a ventura de sonhar. Trata-se de uma infância que não tem fim em uma ou noutra idade, e sim, naquela em que ainda dura em cada um de nós" (DIAS, 2016, p. 165). Este "alerta" a favor da importância da imaginação é uma possibilidade para repensar a geografia e seu ensino de forma integrada com as experiências geográficas dos alunos/estudante.

O ensino de geografia deve ser caracterizado por uma ementa teórica e prática que estimule ao estudante pensar e conhecer sua realidade enquanto potencialidade de seu ser, por meio do cotidiano. Segundo Edgar Morin, "conhecer e pensar não é chegar a uma verdade absolutamente certa, mas dialogar com a incerteza" (MORIN, 2012, p. 59). O princípio da incerteza, como sugere Edgar Morin, deve ser o motor para pensar o ensino de geografia na medida em que o mundo se constitui dentro da complexidade das coisas. As “coisas" ou "objetos" estão no mundo no cambiante fluxo de diferentes interpretações humanas sobre estes. É necessário considerar, mediantes as aulas de geografia, as aventuras cósmicas e telúricas dos estudantes com ícones referenciais, possibilitando ao estudante a capacidade de "enfrentar complexidades" (MORIN, 2012, p. 77).

Alguns estudos, como de Pantoja (2015), já apontam para este sentido de geografia enquanto modo de ser a partir do lugar. À vista disso, devemos ser criativos e ter em mente que todas as perguntas não possuem uma resposta pronta e definitiva, mas várias, compreendendo que a essência da geografia tem ou deve ter como ícone referencial as diversas experiências que homens e mulheres mantêm com seu espaço - linguagem que corresponde, somente, aquém se dedica a construção desse espaço enquanto geográfico. $\mathrm{O}$ sentido do ensino de geografia começa, nesse momento, a possuir um caráter muito mais descritivo que meramente explicativo, afastando-se do apriorismo Kantiano, de modo que “o que nos importa, antes de tudo, é o despertar de uma consciência geográfica [portanto, o enfrentamento das complexidades], através das diferentes intenções sob as quais aparece ao homem [e a mulher] à fisionomia da Terra” (DARDEL, 2015, p. 47).

Pensar a "educação geográfica", como diria Kropotkin (1885), implica em desenvolver estratégias tanto em sala de aula quanto para além desta, ao modo que a “geografia está em todo lugar", segundo Cosgrove (2012) e, portanto, deve ecoar como 
libertação do ser, no mundo, ao despertar a importância da imaginação como recurso de aproximar/apaixonar o estudante pela ciência geográfica. Este fluxo de pensamento inclui, mesmo que timidamente, em pensarmos o humanismo que existe no ensino da geografia porém, muitas vezes abafado por forças conservadoras no ensino - reafirmando o homem, mulher e a criança enquanto seres responsáveis por suas ações e intencionalidades, esbarrando num certo "limite" de liberdade que permita ao outro de ser, como nos ensina Sartre (2014) em sua obra $O$ existencialismo é um humanismo.

Nesse sentido, cabe entender, a partir de então, o humanismo como dimensão essencial na geografia e sua aplicabilidade no ensino e que, inclusive, pode influenciar em estratégias para o estudante pensar sua responsabilidade no mundo para além da lógica mercadológica/funcionalista/tecnicista que inibe a vontade de potência de ser ao conformismo cognitivo, físico e epistemológico em sua complexidade ontológica, moral e cultural. Conforme Edgar Morin, o ensino - em nosso caso de geografia - é mais que uma questão de caráter funcional ou profissional, "mas também uma tarefa de saúde pública: uma missão" (MORIN, 2012, p. 101). Daí o ensino de geografia surgir como forma de libertação e transformação do ser social enquanto ser que pensa e atua em sua condição humana. De um modo geral, estamos indicando para a necessidade e pertinência do ensino de geografia numa perspectiva que respeite o sentido da alteridade, do humanismo como motor para pensar em estratégias para lidar com as incertezas e modos de ser, no mundo.

\section{REFERÊNCIAS}

AB'SÁBER, A. N. O que é ser geógrafo: memórias profissionais. Rio de Janeiro: Record, 2007.

BACHELARD, G. A poética do espaço. In: A filosofia do não; $O$ novo espírito científico; A poética do espaço. Seleção de textos de José Américo Motta Pessanha. Traduções de Joaquim José Moura Ramos et al. São Paulo: Abril Cultural, 1978.

BUTTIMER, A. Social space in interdisciplinary perspective. Geographical review, p. 417-426, 1969.

BRASIL. Secretaria de Educação Fundamental. Parâmetros curriculares nacionais: geografia. Brasilia: MEC/SEF, 1998.

COSGROVE, D. Mundos de significados: geografia cultural e imaginação. In: CORREAA, R. L.; ROSENDAHL, Z. (Org.). Geografia cultural: uma antologia. Rio de Janeiro: EdUERJ, 2012. p. 105-118.

DARDEL, E. O homem e a terra: natureza da realidade geográfica. São Paulo: Perspectiva, 2015. 
DIAS, J. M. T. direitos de aprendizagem em geografia: o lugar em sua potência. Educ. Foco, Juiz de Fora, ed. esp., p. 203-220, fev. 2015.

Infância em gaston bachelard: reflexões sobre o ensino de geografia. Revista da Abordagem Gestáltica - Phenomenological Studies, v. 22, n. 2, p. 162-170, jul./dez. 2016.

ENTRIKI N, J. N. O humanismo contemporâneo em geografia. Boletim de Geografia Teorética, São Paulo, v. 10, n. 19, 1980.

FRANCK, D. Heidegger e o problema do espaço. Trad. de João Paz. Lisboa: Instituto Piaget, 1997.

GEERTZ, C. A interpretação das culturas. Rio de Janeiro: LTC, 2008.

GRATÃO, L. H. B; MARANDOLA JÚNIOR, E. M. Sabor da, na e para Geografia. Geosul, v. 26, n. 51, p. 59-74, 2012.

HUSSERL, Edmund. Ideias para uma fenomenologia pura e para uma filosofia fenomenológica. Aparecida: Idéias \& Letras, 2006.

HEIDEGGER, M. Construir, Habitar, Pensar. Segunda Reunião de Darmastad, Pfullingen. 1954.

Ser e Tempo. 2. ed. Trad. Márcia de Sá Cavalcanti. Petrópolis: Vozes, 1988.

HUSSERL, Edmund. Ideias para uma fenomenologia pura e para uma filosofia fenomenológica. Aparecida: Idéias \& Letras, 2006.

HOLZER, W. Um estudo fenomenológico da paisagem e do lugar: a crônica dos viajantes no Brasil do século XVI. 1998. Tese (Doutorado em Ciências: Geografia Humana) - Faculdade de Filosofia, Letras e Ciências Humanas, Universidade de São Paulo, 1998.

KROPOTKIN, P. What geography ought to be. The Nineteenth century and after: a monthly review, v. 18, n. 106, p. 940-956, 1885.

LÉVINAS, E. Entre nós: ensaios sobre a alteridade. Petrópolis: Editora Vozes, 1997.

LOWENTHAL, D. Geography, experience, and imagination: towards a geographical epistemology. Annals of the association of american geographers, v. 51, n. 3, p. 241 260, 1961.

MORIN, E. A cabeça bem-feita: repensar a reforma, e reformar o pensamento. Tradução de Eloá Jacobina. 20ª Edição. Rio de Janeiro: Bertrand Brasil, 2012.

O Método 3: conhecimento do conhecimento. Tradução de Juremir Machado da Silva. $5^{a}$ Ed. Porto Alegre: Sulina, 2015.

MARANDOLA JR. E. Humanismo e arte para uma geografia do conhecimento. Geosul, v. 25, n. 49, p. 7-26, 2010. 
| Geografia e ensino: um olhar humanista|

| Felipe Kevin Ramos da Silva |

67-79, 2015.

Arqueologia fenomenológica: em busca da experiência. Terra Livre, v. 2, n. 25, p.

MERLEAU-PONTY, M. Fenomenologia da percepção. São Paulo: Martins Fontes, 1994.

NIETZSCHE, F. Vontade de Potência. Tradução: Antonio Carlos Braga e Ciro Mioranza. São Paulo: Editora Escala, 2010.

NUNES, B. A Clave para o Poético. Organização e apresentação: Victor Sales Pinheiro. São Paulo: Companhia das Letras, 2009.

OLIVEIRA, L. Que é geografia. Sociedade \& Natureza, Uberlândia, Ano 11, n. 21-22, p. 89-95, jan./dez. 1999.

O sentido de lugar. In: MARANDOLA JR. E. [et al.] (Org.). Qual o espaço do lugar? São Paulo: Perspectiva, 2014.

Percepção do meio ambiente e geografia: estudos humanistas do espaço, da paisagem. MARANDOLA JR., E.; CAVALCANTE, T. V. (Org.). São Paulo: Cultura Acadêmica, 2017.

PANTOJA, W. W. R. Educação do Campo à beira da "Faixa": a (in) existência do lugar como espacialização do fenômeno. GeoTextos, v. 11, n. 2, p. 221-248, dez. 2015.

RELPH, E. An inquiry into the relations between phenomenology and geography. The Canadian Geographer, v. 14, n. 3, p. 193-201, 1970.

Reflexões sobre a emergência, aspectos e essência de lugar. In: MARANDOLA JR, E. [et al.] (Org.). Qual o espaço do lugar? São Paulo: Perspectiva, 2014.

SAINT-EXPÉRY, A. de. O pequeno príncipe. São Paulo: Escala, 2015.

SILVA, F. K. R. da. Geografia e Fenomenologia: por uma ontologia do espaço e do lugar. 2015. Trabalho de Conclusão de Curso (Graduação em Licenciatura Plena em Geografia) - Universidade do Estado do Pará, Belém-PA, 2015.

Memória, Percepção \& Experiência: a geopoética do habitar ribeirinho na Amazônia-Marajoara (Pará). 2017. Dissertação (Mestrado em Geografia) - Instituto de Filosofia e Ciências Humanas, Universidade do Federal do Pará, Belém-PA, 2017.

SARTRE, Jean-Paul. O existencialismo é um humanismo. Trad. de João Batista Kreuch. 3. ed. Rio de Janeiro: Vozes editora, 2014.

SILVA, A. C. da. A aparência, o Ser e a forma - geografia e método. GEOgraphia, v. 2, n. 3, p. 7-25. 2009.

TUAN, Yi-Fu. Humanistic geography. Annals of the Association of American Geographers, v. 66, n. 2, p. 266-276, 1976. 
Espaço, tempo, lugar: um arcabouço humanista/Space, time, place: a humanistic frame. Geograficidade, v. 1, n. 1, p. 04-15, 2011. 2012.

Topofilia: um estudo da percepção. Trad.: Lívia de Oliveira. Londrina: Eduel,

Espaço e lugar: a perspectiva experiência. Trad. Lívia de oliveira. Londrina: Eduel, 2013.

WRIGHT, J. K. Terrae incognitae: o lugar da imaginação na geografia. Geograficidade, v. 4, n. 2, p. 04-18, 2014. 